\title{
Efeito da adição de microssílica na hidratação de óxido de magnésio em concretos refratários"
}

\section{(Microsilica addition as anti-hydration technique of magnesia in refractory castables)}

\author{
R. Salomão $o^{1}$, V. C. Pandolfelli \\ Grupo de Engenharia de Microestrutura de Materiais - GEMM \\ Departamento de Engenharia de Materiais, Universidade Federal de S. Carlos \\ Rod. Washington Luiz, km 235, C.P. 676, S. Carlos, SP 13565-905 \\ rflslm@gmail.com,vicpando@power.ufscar.br
}

\begin{abstract}
Resumo
A adição de microssílica $\left(\mathrm{SiO}_{2}\right)$ às formulações de concretos refratários contendo óxido de magnésio (MgO) é um conhecido modo de melhorar suas propriedades reológicas e trabalhabilidade. Na literatura, diversos estudos descrevem esse efeito como sendo causado pela formação de um silicato hidratado de magnésio na superfície das partículas de MgO, responsável pela diminuição de sua reatividade. No entanto, os potenciais benefícios em relação à redução dos danos causados pela hidratação do $\mathrm{MgO}$ em concretos refratários que esse mecanismo pode proporcionar não foram avaliados de forma sistêmica. Neste trabalho, o impacto da adição de microssílica na velocidade de hidratação de sínter de $\mathrm{MgO}$ em concretos refratários foi avaliado por meio de medidas de fluidez sob vibração, expansão volumétrica aparente, resistência mecânica e comportamento de secagem. Entre outros pontos, foi verificada uma significativa redução na velocidade de hidratação do $\mathrm{MgO}$, bem como nos danos mecânicos causados à estrutura do concreto. Palavras-chave: óxido de magnésio, microssílica, hidratação, concretos refratários.
\end{abstract}

Abstract

Magnesia hydration is an important concern when it is added to refractory castables. The volumetric expansion that follows this reaction can cause the material's breakdown. Recent reports in literature suggest that if this reaction could be halted or slowed down, significant benefits in castables properties would be attained. In this work, microsilica addition was employed as a magnesia anti-hydration technique (MAHT). Using apparent volumetric expansion (AVE) and mechanical strength measurements, the drying behavior and X-ray diffraction, an anti-hydration mechanism based on the generation of protective magnesium silicate coating is proposed. Its limitations and effects upon castables processing were also evaluated.

Keywords: magnesia, hydration, microsilica, refractory castables.

\section{INTRODUÇÃO}

A adição de óxido de magnésio (MgO ou magnésia) em formulações de concretos refratários é geralmente limitada a um teor máximo de $10 \%$ peso de partículas grosseiras $\left(\mathrm{D}_{\text {Particula }}>50 \mu \mathrm{m}\right)$ devido à expansão volumétrica que acompanha a reação de hidratação desse óxido $[1,2]$. Essa expansão está relacionada à diferença de densidade entre o óxido $\left(\rho_{\mathrm{MgO}}=3,5 \mathrm{~g} / \mathrm{cm}^{3}\right)$ e o hidróxido $\left(\rho_{\mathrm{Mg}(\mathrm{OH}) 2}=2,4 \mathrm{~g} /\right.$ $\mathrm{cm}^{3}$ ) de magnésio e, com freqüência, causa a ruptura do material [2-4]. Como concretos refratários contendo $\mathrm{MgO}$ possuem grande importância tecnológica, diversos trabalhos na literatura descreveram técnicas anti-hidratação (TAH),

${ }^{1}$ Endereço Atual: Centro de Engenharia, Modelagem e Ciências Sociais Aplicadas, Universidade Federal do ABC, Rua da Catequese, 242 Santo André-SP, 09090-400, Brasil.

* Premio Congresso Brasileiro de Cerâmica, 2007. como possíveis soluções para esse problema [4-9].

As TAH foram desenvolvidas para evitar os danos causados pela hidratação do $\mathrm{MgO}$ por meio da interrupção dessa reação. Trabalhos recentes mostraram que, se a velocidade de hidratação do $\mathrm{MgO}$ for reduzida durante as etapas de mistura, cura e secagem, as propriedades mecânicas dos concretos podem ser significativamente melhoradas [3]. A adição de microssílica é uma das TAH's mais exploradas em concretos devido ao seu baixo custo e efetividade. Diversos trabalhos registraram a combinação de $\mathrm{MgO}-\mathrm{SiO}_{2}$ e $\mathrm{Al}_{2} \mathrm{O}_{3}-\mathrm{MgO}-\mathrm{SiO}_{2}$ em concretos refratários [6, 8, 10-12]. Os efeitos mais bem documentados da adição de microssílica são o aumento da fluidez do concreto [13] e a atenuação das tensões de compressão geradas durante a formação de espinélio $\left(\mathrm{Al}_{2} \mathrm{MgO}_{4}\right)$ [12]. No primeiro caso, devido à sua forma esférica, as partículas de microssílica produzem um efeito lubrificante, reduzindo fricção entre os componentes do concreto e aumentando sua fluidez $[13,14]$. 
Além disso, a presença de uma pequena quantidade de compostos de baixa refratariedade (como cordierita, $2 \mathrm{MgO} .2 \mathrm{Al}_{2} \mathrm{O}_{3} .5 \mathrm{SiO}_{2}$ ) permite uma melhor acomodação das tensões expansivas geradas durante a espinelização in situ na estrutura dos concretos [12]. Outro importante aspecto é o efeito ligante que a associação de microssílica e magnésia promove $[14,15]$. Esse mecanismo é descrito como a geração de um gel hidratado à base de silicato de magnésio $\left(\mathrm{MgHSiO}_{4} \cdot n \mathrm{H}_{2} \mathrm{O}\right)$ entre as partículas de óxido ou hidróxido de magnésio e microssílica ou sílica coloidal [10, 13-15]. Essa reação pode reduzir a velocidade de hidratação do $\mathrm{MgO}[10,15]$ e, em alguns casos, pode ser utilizada na consolidação dos concretos, sem o uso de outros ligantes [12]. No entanto, os detalhes desse mecanismo ainda não foram totalmente explorados devido às dificuldades experimentais e ao interesse tecnológico envolvido.

Baseado nos recentes avanços obtidos em relação ao entendimento do comportamento de hidratação do $\mathrm{MgO}[2$, $3]$, o presente trabalho teve por objetivo investigar o impacto da adição de microssílica na hidratação do $\mathrm{MgO}$ e seus efeitos nas propriedades de concretos refratários. Utilizando medidas de fluidez e testes de hidratação-desidratação [3], medidas de resistência mecânica e expansão volumétrica aparente (EVA) [2], perfis de velocidade de secagem [16] e difração de raios $\mathrm{X}$, os autores propuseram um mecanismo de proteção baseado na solubilidade da sílica amorfa [17]. Os potenciais benefícios e limitações dessa técnica antihidratação também são apresentados.

\section{MATERIAIS E MÉTODOS}

Uma composição de concreto refratário vibrável de alta alumina e contendo $6 \%$ peso de sínter de $\mathrm{MgO}\left(\mathrm{D}_{50}=15 \mu \mathrm{m}\right.$, Magnesita S.A., Brasil), $6 \%$ peso de cimento de aluminato de cálcio (CA14M, Almatis, EUA), 5,5\% peso de água, $0,25 \%$ peso de um dispersante à base de poli(etileno glicol) (Bayer, Alemanha) foi empregada nos testes (descrição detalhada da composição pode ser encontrada na Tabela I). Microssílica (971-U, Elkem, Noruega) foi adicionada à composição em diferentes quantidades $(0,25-2 \%$ peso). Composições de referência sem magnésia e sem-magnésiae-sem-microssílica também foram testadas (o sínter de $\mathrm{MgO}$ foi substituído por aluminas calcinadas de granulometria equivalente).

As formulações de concreto foram misturadas e homogeneizadas em um misturador planetário por 10 minutos e, ao fim desse tempo, sua fluidez foi medidas após $10 \mathrm{~s} \mathrm{de}$ vibração ( $50 \%$ da potência máxima do equipamento). Em seguida, as formulações foram moldadas moldes cilíndricos: 40 x $40 \mathrm{~mm}$, para testes de secagem e hidratação e medidas de resistência mecânica, e $70 \times 70 \mathrm{~mm}$, para avaliação da expansão volumétrica aparente (EVA) [2]. O período inicial de cura foi realizado em uma câmara climatizada Voetch 2020, a $8{ }^{\circ} \mathrm{C}$, durante $24 \mathrm{~h}$. Essa condição foi empregada para garantir um mínimo de resistência mecânica para desmoldagem, sem hidratação significativa do $\mathrm{MgO}$ [2]. Os testes de hidratação foram realizados após esse período,
Tabela I - Concreto refratários e suspensões de sínter de $\mathrm{MgO}$ estudados

[Table I - Refractory castable and magnesia sinter suspension compositions analyzed]

\begin{tabular}{ll}
\hline Matérias primas & \%peso \\
\hline Concreto refratário com sínter de $\mathrm{MgO}$ & \\
\hline Aluminas eletrofundidas brancas e & $86-88$ \\
calcinadas * & 6 \\
Cimento de aluminato de cálcio ** & 6 \\
Sinter de $\mathrm{MgO}(98 \%$ peso de $\mathrm{MgO}) * * *$ & $0-2$ \\
Microssílica **** & 5,5 \\
Água & 0,25 \\
Dispersante (à base de polietileno glicol) & \\
Suspensões de sínter de MgO & $90-100$ \\
Sinter de MgO (98\%peso de MgO) *** & $0-10$ \\
Microssílica **** & 30 \\
Água & 1,5 \\
Dispersante (à base de polietileno glicol) & \\
\hline
\end{tabular}

* Elfusa, Brasil; ** Almatis, EUA;

*** Magnesita S.A., Brasil; **** Elken, Noruega

expondo as amostras a um ambiente úmido, a $50{ }^{\circ} \mathrm{C}$, por 7 dias. Durante esse período, a resistência mecânica, o perfil de velocidade de secagem e a expansão volumétrica das amostras foram avaliados a cada $24 \mathrm{~h}$.

A resistência mecânica das amostras (secas a $350{ }^{\circ} \mathrm{C}$, por $5 \mathrm{~h}$, com uma taxa de aquecimento de $10{ }^{\circ} \mathrm{C} / \mathrm{min}$ ) foi medida por compressão diametral (ASTM C496-96) em um equipamento TestStar II, utilizando-se uma taxa de aplicação de carga constante de $40 \mathrm{~N} / \mathrm{s}$.

Os testes de secagem foram conduzidos em amostras úmidas, até $600^{\circ} \mathrm{C}$ e sob uma taxa de aquecimento de $10^{\circ} \mathrm{C} /$ $\mathrm{min}$, em um equipamento termogravimétrico [16]. Variação de massa e a temperatura nas amostras foram simultaneamente registradas. $\mathrm{O}$ parâmetro $\mathrm{W}$ e sua taxa de variação com o tempo (dW/dt, \%/min), que representa a velocidade de secagem, foram calculados utilizando as equações

$$
\begin{aligned}
& \mathrm{W}(\%)=100 \times\left(\mathrm{M}_{0}-\mathrm{M}\right) /\left(\mathrm{M}_{0}-\mathrm{M}_{\mathrm{F}}\right) \\
& (\mathrm{dW} / \mathrm{dt})_{\mathrm{i}}=\left(\mathrm{W}_{(\mathrm{i}+10)}-\mathrm{W}_{(\mathrm{i}-10)}\right) /\left(\mathrm{t}_{(\mathrm{i}+10)}-\mathrm{t}_{(\mathrm{i}-10)}\right)
\end{aligned}
$$

onde $M$ é valor instantâneo de massa registrado em um determinado tempo $t_{i}$, durante o aquecimento, $M_{0}$ e $M_{F}$ são, respectivamente, os valores das massas inicial e final das amostras testadas.

A medida de expansão volumétrica aparente (EVA) consiste em media as dimensões de amostras cilíndricas (70 $\mathrm{mm} \times 70 \mathrm{~mm}$ ) durante sua exposição a uma determinada condição de umidade e temperatura, ao longo de 7 dias [2]. A EVA foi calculada considerando-se o volume inicial das amostras como referência, por meio das equações 


$$
\begin{aligned}
& \mathrm{V}_{\mathrm{i}}=\mathrm{H}_{\mathrm{i}} \times \pi \times\left(\mathrm{D}_{\mathrm{i}}-2 \mathrm{t}\right)^{2} / 4 \\
& \operatorname{EVA}(\%)=100 \times\left(\left(\mathrm{V}_{\mathrm{E}}-\mathrm{V}_{0}\right) / \mathrm{V}_{0}\right)
\end{aligned}
$$

A equação $C$ é utilizada para calcular o volume das amostras cilíndricas a um dado tempo, onde $\mathrm{V}_{\mathrm{i}}$ é o volume, $\mathrm{H}$ é a altura, D é o diâmetro e $e$ é a espessura da parede do molde (flexível e anti-aderente). Para o parâmetro EVA, $\mathrm{V}_{0}$ é o volume inicial da amostra e $V_{E}$ seu correspondente após a hidratação e expansão. Maiores detalhes da técnica e suas aplicações podem ser encontrados na literatura [2].

Para identificar os compostos formados durante a hidratação do $\mathrm{MgO}$ em presença de microssílica, suspensões aquosas de sínter de $\mathrm{MgO}$ contendo diferentes teores de microssílica (até $10 \%$ peso), $25 \%$ peso de água e $1,5 \%$ de dispersante foram preparadas. A mistura, moldagem e cura dessas amostras foram conduzidas nas mesmas condições empregadas para os concretos. Após o período de hidratação, as amostras foram secas em sílica gel, moídas $\left(\mathrm{D}_{\text {Partícula }}<45 \mu \mathrm{m}\right)$ e caracterizadas por difração de raios $\mathrm{X}$ (Siemens D 5000, Kristalloflex 710, $\mathrm{K} \alpha=\mathrm{Cu}$, Ni filter). Esses resultados serão apresentados com a intensidade relativa do pico principal de difração de cada composto identificado.

\section{RESULTADOS E DISCUSSÃO}

A adição de microssilica reduziu o impacto da hidratação do $\mathrm{MgO}$, como pode ser observado nos resultados de medida de EVA (Fig. 1a) e resistência mecânica (Fig. 1b). Para a amostra com $\mathrm{MgO}$ e sem microssílica, a resistência inicial (obtida após $24 \mathrm{~h}$ a $8{ }^{\circ} \mathrm{C}$ começa a cair após o terceiro dia de exposição à umidade, quando os primeiros sinais de EVA são verificados. Como na amostra de referência (sem MgO, Fig. 1c) os níveis de resistência mecânica aumentaram continuamente com o tempo de cura (resultados similares podem ser encontrados na literatura [18]), esse comportamento pode ser entendido como um indicativo de que o tensionamento causado pela hidratação do $\mathrm{MgO}$ atingiu os limites de resistência mecânica da estrutura dos concretos [2]. Por outro lado, quanto maior o teor de microssílica, menor os valores de EVA (para as amostras com 1 e $2 \%$ peso de microssílica a EVA não foi observada) e maior a resistência mecânica após 7 dias de cura. A Fig. 2 apresenta o aspecto dessas amostras.

Os resultados de EVA e medida de resistência mecânica podem ser associados ao perfil de velocidade de secagem das amostras antes (Fig. 3a) e após (Fig. 3b) à exposição à condição de hidratação. Antes da hidratação do $\mathrm{MgO}$ (após $24 \mathrm{ha} 8^{\circ} \mathrm{C}$ ), a principal diferença observada no comportamento de secagem das composições contendo ou não microssílica foi a pequena redução na intensidade do pico relacionado à ebulição da água livre (entre 25 e $40 \mathrm{~min}$ ou entre $100-300{ }^{\circ} \mathrm{C}$ ). Esse efeito é causado pela redução de permeabilidade que o melhor empacotamento decorrente da adição de microssílica causa [11, 14]. Os picos correspondentes à decomposição dos hidratos do cimento e do $\mathrm{MgO}$ apresentaram os mesmos baixos níveis de intensidade em ambos os casos (resultados similares podem ser
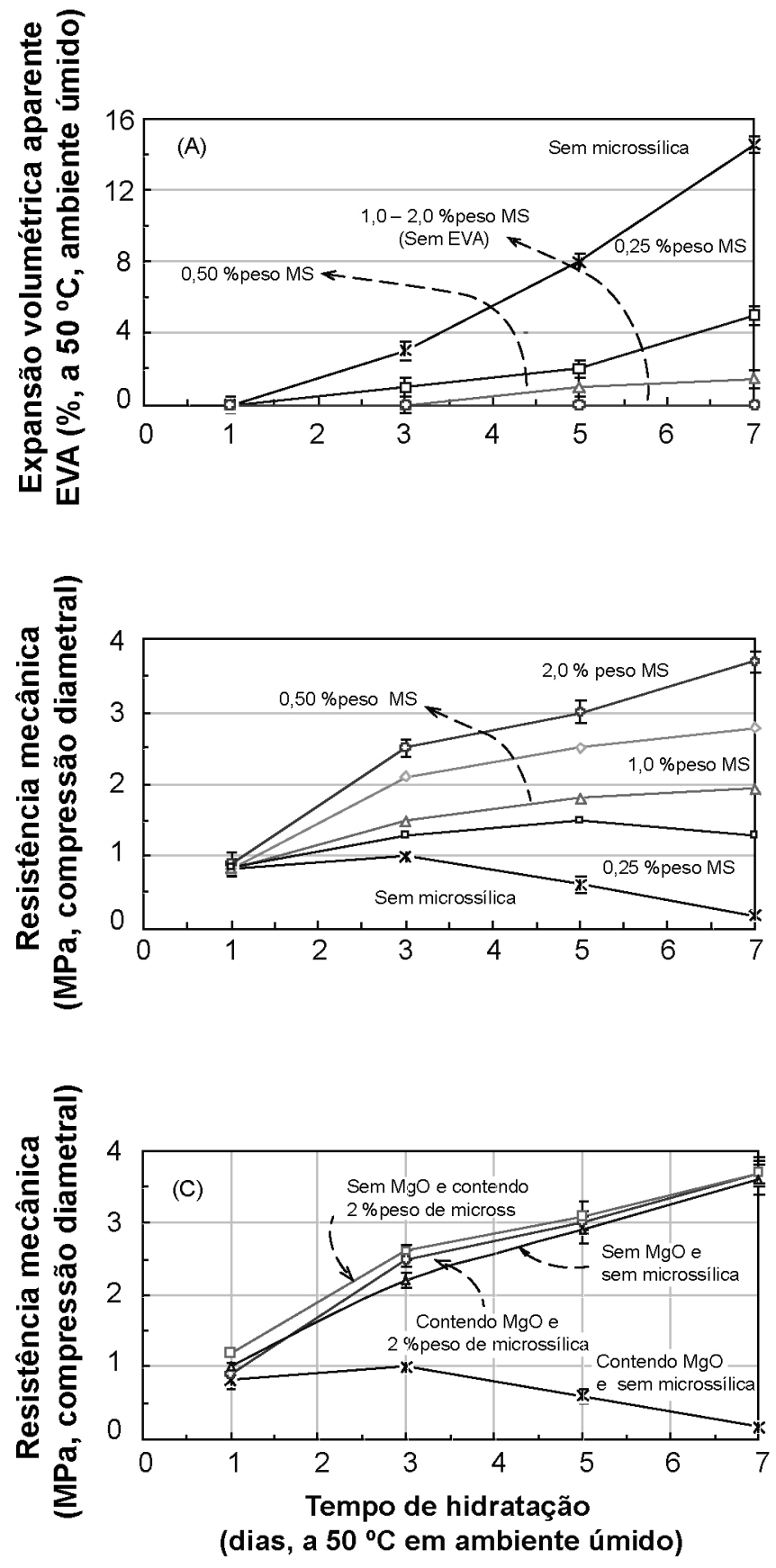

Figura 1: Testes de hidratação (até 7 dias a $50{ }^{\circ} \mathrm{C}$, em ambiente úmido): a) expansão volumétrica aparente (EVA), b) evolução da resistência mecânica e c) formulações de referência (sem $\mathrm{MgO}$ e sem-MgO-e-sem-microssílica).

[Figure 1: Hydration tests (up to 7 days, at $50{ }^{\circ} \mathrm{C}$, in humid environment): a) apparent volumetric expansion (AVE), b) evolution of mechanical strength and c) reference samples (magnesia-free and magnesia-and-microsilica-free)].

encontrados na literatura $[2,18])$.

Após o período de hidratação (7 dias a $50{ }^{\circ} \mathrm{C}$, Fig. 3b), a adição de microssílica modificou consideravelmente os perfis de velocidade de secagem. Os três picos principais observados podem ser descritos como correspondentes à 


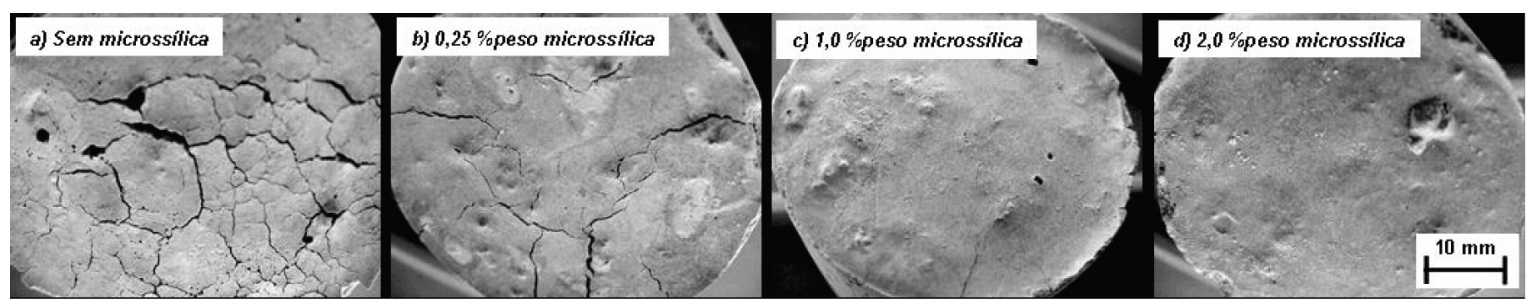

Figura 2: Aspecto das amostras de concreto refratário contendo $\mathrm{MgO}$ e diferentes teores de microssílica (após 7 dias a $50{ }^{\circ} \mathrm{C}$, em ambiente úmido).

[Figure 2: Aspect of the magnesia containing castables with different amounts of microsilica (after 7 days at $50{ }^{\circ} \mathrm{C}$ in humid environment)].

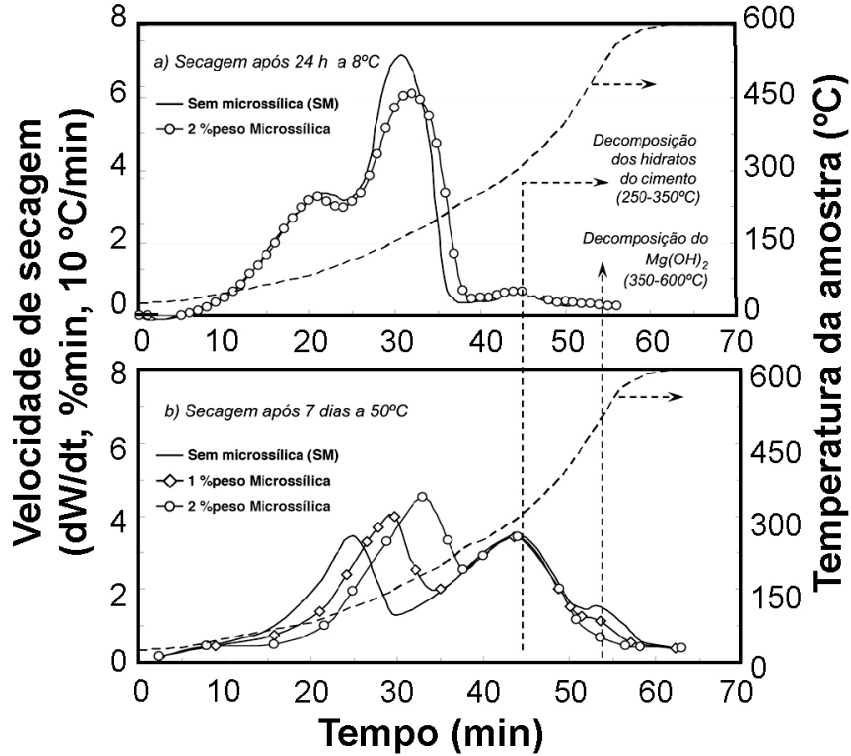

Figura 3: Perfil de velocidade de secagem para concretos contendo $\mathrm{MgO}$ e microssílica a) antes $\left(24 \mathrm{~h} \mathrm{a} 8{ }^{\circ} \mathrm{C}\right)$ e b) após $\left(7\right.$ dias a $\left.50^{\circ} \mathrm{C}\right)$ a hidratação do $\mathrm{MgO}$

[Figure 3: Drying rate profiles for microsilica containing castables a) before $\left(24 \mathrm{~h}\right.$ at $\left.8{ }^{\circ} \mathrm{C}\right)$ and b) after $\left(7\right.$ days at $\left.50{ }^{\circ} \mathrm{C}\right)$ magnesia hydration].

ebulição da água $\left(110-300^{\circ} \mathrm{C}\right)$ e à decomposição dos hidratos do cimento $\left(300-400{ }^{\circ} \mathrm{C}\right)$ e do $\mathrm{Mg}(\mathrm{OH}) 2\left(400-600^{\circ} \mathrm{C}\right)[2,3]$. $\mathrm{O}$ aumento no teor de microssílica adicionado não afetou a hidratação do cimento, mas reduziu consideravelmente o pico de decomposição do $\mathrm{Mg}(\mathrm{OH})_{2}$, indicando que a velocidade de hidratação do $\mathrm{MgO}$ foi reduzida para a amostra contendo $1 \%$ peso de microssílica e totalmente inibida para aquela com $2 \%$ peso. Outra importante conseqüência da adição de microssílica está associada ao aumento de intensidade do pico de ebulição da água e seu deslocamento para maiores temperaturas. Trabalhos na literatura sobre o comportamento de secagem de concretos refratários descrevem esse efeito como típico de materiais com baixa porosidade e permeabilidade $[16,18]$, indicando assim a ausência de trinca geradas pela hidratação do MgO. Esses resultados associados àqueles apresentados na Figura $1 \mathrm{c}$ indicam que o mecanismo pelo qual a adição de microssílica

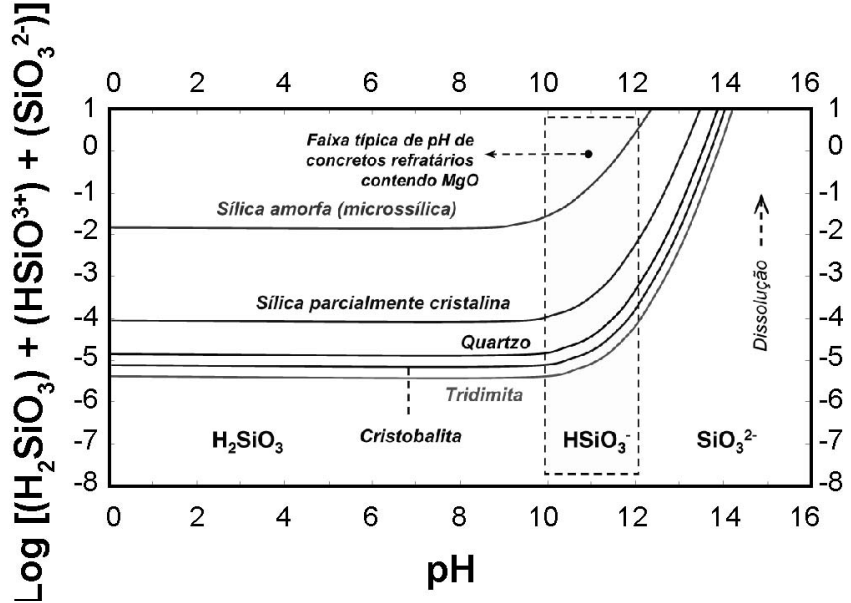

Figura 4: Comportamento de solubilidade da sílica. [Figure 4: Silica's dissolution behavior (14, 17)]

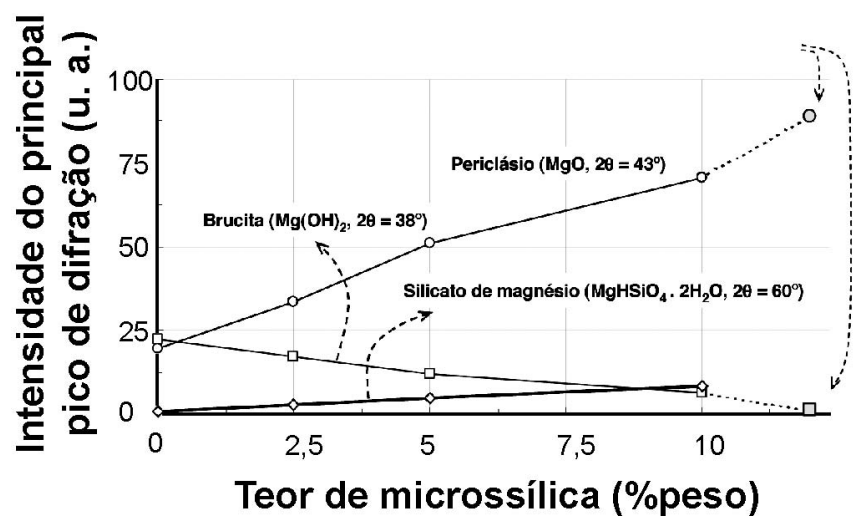

Figura 5: Intensidade dos picos principais de difração de raios $\mathrm{X}$ para suspensões aquosas de $\mathrm{MgO}$ e microssílica (após 7 dias a $50{ }^{\circ} \mathrm{C}$ ). [Figure 5: X-ray diffraction for magnesia-microsilica aqueous suspensions, after 7 days at $\left.50^{\circ} \mathrm{C}\right]$.

minimiza os danos por EVA está baseado principalmente na interrupção da reação de hidratação do $\mathrm{MgO}$ e não no aumento de resistência mecânica dos concretos. Para avaliar essa hipótese, eles foram associados ao comportamento de dissolução da sílica amorfa [17] (Fig. 4), à difração de raios $\mathrm{X}$ das suspensões de $\mathrm{MgO}$ e microssílica após hidratação (Figs. 5 e 6) e às medidas de fluidez do concreto (Fig. 7). 


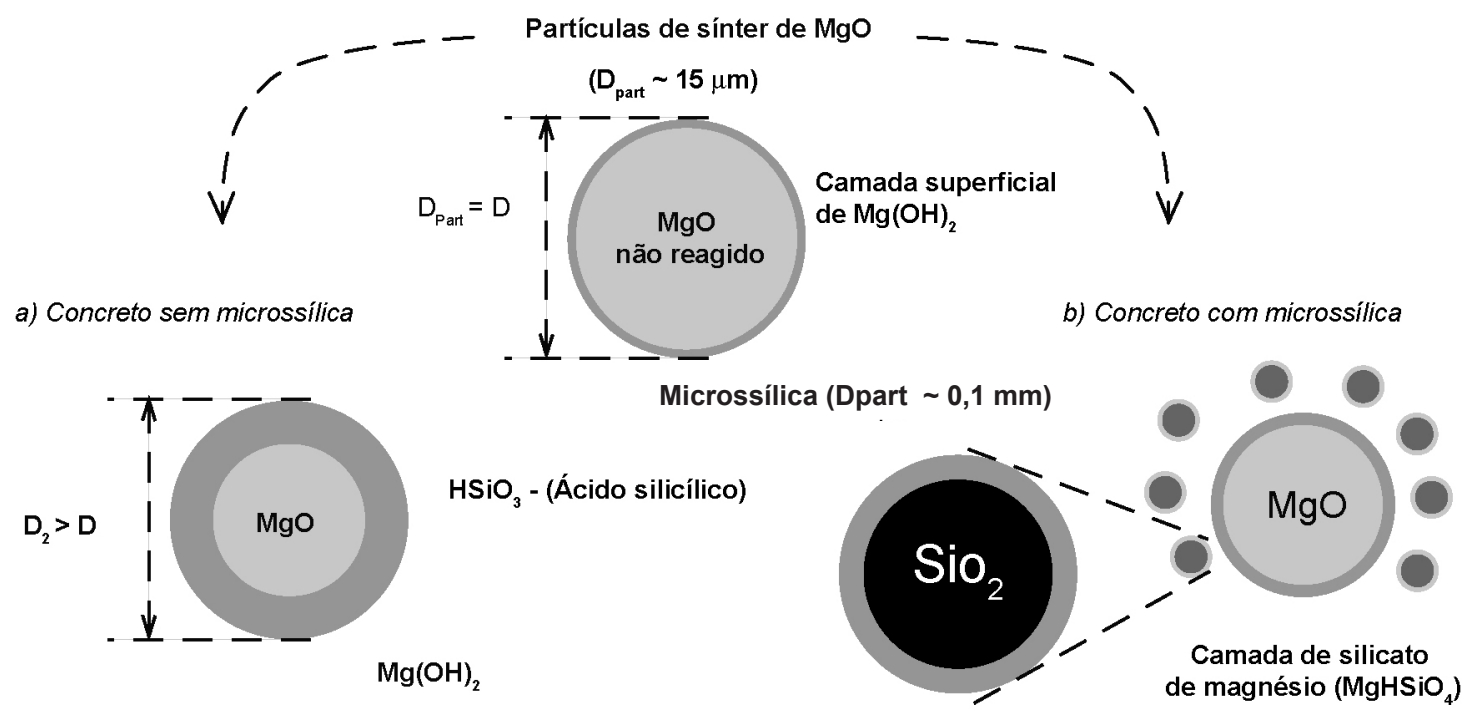

Figura 6: Representação esquemática do mecanismo anti-hidratação da microssílica para o MgO.

[Figure 6: Schematic view of microsilica's anti-hydration mechanism for magnesia].

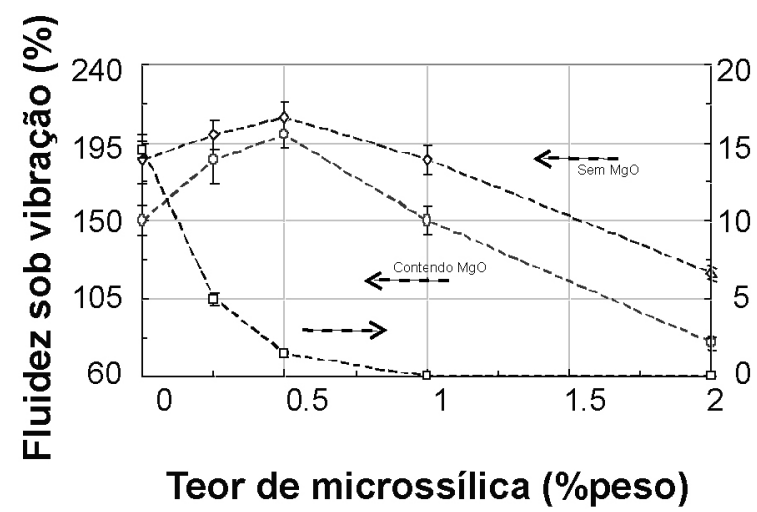

Teor de microssílica (\%peso)

Figura 7: impacto da adição de microssílica na fluidez sob vibração e expansão volumétrica aparente dos concretos contendo $\mathrm{MgO}$.

[Figure 7: Impact of microsilica content on castables'flowability under vibration and apparent volumetric expansion (AVE)].

O comportamento de dissolução da sílica amorfa em função do $\mathrm{pH}$ do ambiente é baseado no diagrama de Pourbaix do silício [17, 20, 21] e foi recentemente empregado no estudo da atuação dos pós de alumínio e silício como antioxidantes em concretos refratários contendo carbono. A Fig. 4 indica que uma suspensão de sílica (ou de silício metálico parcialmente oxidado) é estável em uma ampla faixa de pH (0-10) [14, 20, 21]. No entanto, quando uma fonte de sílica amorfa de alta área superficial (como a microssílica) é exposta a um ambiente altamente alcalino $(10 \leq \mathrm{pH} \leq$ 12, como o ambiente encontrado em concretos refratários contendo $\mathrm{MgO}$ e cimento de aluminato de cálcio), ela se dissolve parcialmente, gerando ácido silicílico $\left(\mathrm{HSiO}_{3}\right)[14$, $15,20]$. Se essa dissolução ocorrem em presença de $\mathrm{MgO}$, o ácido silicílico é rapidamente atraído pela camada de $\mathrm{Mg}(\mathrm{OH})_{2}$ que recobre a superfície das partículas de $\mathrm{MgO}$, gerando uma camada de silicato de magnésio hidratado [15], de baixa cristalinidade e descrita pela Equação E:

$\left(\mathrm{HSiO}_{3}\right)^{-}+\mathrm{Mg}(\mathrm{OH})_{2}+\mathrm{H}_{2} \mathrm{O} \rightarrow \mathrm{MgHSiO}_{4} \cdot 2 \mathrm{H}_{2} \mathrm{O}$

O silicato de magnésio apresenta baixa solubilidade em água (em pH alcalino) [15] e, devido a isso, atua como camada protetora inibindo a hidratação do $\mathrm{MgO}$. Esse efeito pode ser claramente observado nos resultados de difração de raios $\mathrm{X}$ das suspensões de $\mathrm{MgO}$ e microssílica (Fig. 5). Eles indicam que, após o período de hidratação (7 dias a 50 ${ }^{\circ} \mathrm{C}$ ), na amostra sem microssílica, houve a formação de um sistema composto por $\mathrm{MgO}$ anidro (periclásio, $2 \theta=43^{\circ}$ ) e parcialmente hidratados (brucita, $2 \theta=43^{\circ}$ ). Com a adição de microssílica, a fração de brucita começa a diminuir e a intensidade do pico de difração do periclásio se aproxima do nível observado para a amostra de referência (como recebida e sem hidratação). Ao mesmo tempo, também pode ser observado o aumento da intensidade do pico referente à camada protetora de silicato de magnésio $\left(\mathrm{MgHSiO}_{4} \cdot 2 \mathrm{H}_{2} \mathrm{O}\right.$, $2 \theta=60^{\circ}$ ). A baixa intensidade desse pico é devida à reduzida cristalinidade desse composto e à pequena quantidade formada (uma fina camada na superfície das partículas de $\mathrm{MgO}$ ). A Fig. 6 mostra uma representação esquemática desse mecanismo.

Os resultados das Figs. 1a, 3b e 5 indicam que a eficiência dessa técnica depende fortemente das quantidades de ácido silicílico e, conseqüentemente, microssílica disponíveis para reagir com o $\mathrm{MgO}$, de modo a satisfazer a estequiometria da reação. Esse aspecto apresenta uma boa correlação com o impacto da adição de microssílica à fluidez dos concretos (Fig. 7). Devido ao efeito lubrificante de suas partículas esféricas, a adição de microssílica às formulações de 
concretos refratários pode aumentar sua fluidez [13]. O teor otimizado de microssílica para cada formulação é atingido quando todas as partículas do concreto são recobertas por uma camada de partículas de microssílica, de modo análogo à ação dos dispersantes. Acima dessa quantidade, a adição de microssílica passa a requerer maiores quantidades de água, devido ao aumento da área superficial do concreto, causando a redução da fluidez.

Para as composições com e sem $\mathrm{MgO}$ testadas, os maiores níveis de fluidez foram obtidos para um teor de microssílica igual a $0,5 \%$ peso. Como teores acima desse valor (pelo menos $1 \%$ peso) foram requeridos para reduzir significativamente a EVA (Fig. 1a) e a velocidade de hidratação do $\mathrm{MgO}$ (Fig. 2b), pode-se afirmar que a adição de microssílica atua favoravelmente como mecanismo anti-hidratação quando o teor de microssílica adicionado à formulação é suficiente para recobrir a superfície de todas as partículas do concreto. Baseado nisso, é razoável assumir que, composições com maiores áreas superficiais (geralmente, aquelas que apresentam maiores teores de partículas finas, com as autoescoantes) necessitariam de maiores teores de microssílica para inibir totalmente a hidratação do $\mathrm{MgO}$ e vice-versa.

\section{CONCLUSÕES}

A adição de microssílica pode atuar favoravelmente reduzindo os efeitos deletérios da hidratação do $\mathrm{MgO} \mathrm{em}$ concretos refratários. Seu mecanismo anti-hidratação está baseado na geração de uma barreira protetora na superfície das partículas de $\mathrm{MgO}$. Em $\mathrm{pH}$ alcalino (como o dos concretos contendo $\mathrm{MgO}$ ), a microssílica se dissolve parcialmente gerando ácido silicílico, $\left(\mathrm{HSiO}_{3}\right)^{-}$, que é atraído pela camada de $\mathrm{Mg}(\mathrm{OH})_{2}$ presente na superfície das partículas de $\mathrm{MgO}$. $\mathrm{O}$ resultados dessa reação de neutralização ácido-base é a geração de uma barreira insolúvel de silicato de magnésio hidratado, que reduz a velocidade de hidratação do $\mathrm{MgO}$. Os melhores resultados desse mecanismo foram obtidos quando todas as partículas do concreto foram recobertas por uma camada de partículas de microssílica. Essa condição implica que a quantidade mínima de microssílica necessária para esse mecanismo seja definida pela área superficial do concreto e pelo teor de $\mathrm{MgO}$ na formulação. Aspectos importantes dessa técnica anti-hidratação (TAH): 1) é de baixo custo e pode ser facilmente aplicada às formulações de concretos já existentes, com pequenas modificações; 2) para teores de $\mathrm{MgO}$ abaixo de $10 \%$ peso, o teor de microssílica requerido (1-2\% peso) não causa redução significativa de refratariedade e 3) em sistemas $\mathrm{Al}_{2} \mathrm{O}_{3} / \mathrm{MgO}$, a presença de microssílica gera benefícios extras, aumentando a fluidez dos concretos e ajudando na acomodação das tensões expansivas geradas na espinelização in situ, com descrito na literatura [14, 16, 17].

\section{AGRADECIMENTOS}

À Fundação de Apoio à Pesquisa no Estado de São Paulo (FAPESP), à Alcoa Alumínio e à Magnesita S.A. pelo suporte fornecido.

\section{REFERÊNCIAS}

[1] A. Kitamura, K. Onizuka, K. Tanaka, Taikabutsu Overseas 16, 3 (1995) 3-11.

[2] R. Salomão, L. R. M. Bittencourt, V. C. Pandolfelli, Ceram. Int. 33, 5 (2006) 803-810.

[3] R. Salomão, V. C. Pandolfelli, "Hydration dehydration behavior of magnesia sinter in refractory castables", Ceram. Int. (2007) aceito.

[4] A. Kaneyasu, S. Yamamoto, A. Yoshida, Taikabutsu Overseas 17, 2 (1996) 21-26.

[5] Y. Koga, M. Sato, K. Sekeguchi, S. Iwamoto, Taikabutsu Overseas 18, 1 (1997) 43-47.

[6] M. M. Ali, A. K. Mullick, Cement and Concrete Res. 28, 11 (1998) 1585-1594.

[7] S. Chen, G. Chen, J. Cheng, J. Am. Ceram. Soc. 83, 7 (2000) 1810-1812.

[8] C. Ödegård, Proc. UNITECR 2001, Cancun (2001) 4-7. [9] A. Yoschida, T. Nemoto, A. Kaneyasu, Proc. UNITECR 2003, Osaka (2003) 21-30.

[10] K. Ghanbari Ahari, J. H. Sharp, W. E. Lee, J. Eur. Ceram. Soc. 23 (2003) 3071-3077.

[11] B. Sandberg, T. Mosberg, Ceram. Trans. 4 (1989) 245 258.

[12] B. Sandberg and B. Myhre, Proc. UNITECR 1995, Kyoto (1995) 19-22.

[13] B. Myhre, Proc. $3^{\text {rd }}$ India Int. Refract. Cong., Calcutta (1998) 11-13.

[14] R. K. Iler, The Chemistry of Silica, Wiley, New York (1979) pp. 3-104.

[15] J. Temuujin, K. Okada, K. J. D. MacKenzie, J. Solid State Chem. 138 (1998) 169-177.

[16] M. D. M. Innocentini, F. A. Cardoso, M. M. Akyioshi, V. C. Pandolfelli, J. Am. Ceram. Soc. 86, 7 (2003) 11461148.

[17] M. Pourbaix, Atlas of Electrochemical Equilibria in Aqueous Solution, Pergamon Press, New York (1966) pp. 458-463.

[18] F. A. Cardoso, M. D. M. Innocentini, M. M. Akyioshi, V. C. Pandolfelli, J. Eur. Ceram. Soc. 24, 7 (2004) 20732078.

[19] V. G. Domiciano, J. R. Garcia, V. C. Pandolfelli, Am. Ceram. Soc. Bull. 84, 5 (2005) 9101-9105.

[20] V. G. Domiciano, I. R. Oliveira, R. Salomão, V. C. Pandolfelli, Am. Ceram. Soc. Bull. 84, 10 (2005) 31-36.

(Rec. 12/08/2007, Ac. 31/08/2007) 